\title{
PAPELÃO E ECODESIGN: DESENVOLVIMENTO DE UM FECHAMENTO VERTICAL
}

\section{CARDBOARD AND ECODESIGN: DEVLOPMENT OF A VERTICAL PARTITION}

\section{Lucas Rosse Caldas, M.Sc. (FAU/UFRJ)}

\author{
Palavras Chave \\ Papelão; Ecodesign; Fechamento Vertical; Experiência de Ensino
}

\section{Key Words}

Cardboard; Ecodesign; Vertical Partition; Teaching Experience

\begin{abstract}
RESUMO
Esta pesquisa teve como objetivo a apresentação e avaliação, conforme princípios de ecodesign, de um protótipo de fechamento vertical utilizando papelão ondulado como matéria prima. $O$ estudo foi realizado a partir da pesquisa bibliográfica e registros fotográficos e documentais realizados no segundo semestre de 2017 da disciplina de Processos Construtivos III, da Faculdade de Arquitetura e Urbanismo da Universidade Federal do Rio de Janeiro (FAU/UFRJ). O projeto e execução do protótipo foi realizado por um grupo de dez alunos, que escolheram o papelão como único material para a confecção do protótipo. Essa escolha surgiu da diretriz de projeto que sugere que moradores de um alojamento da UFRJ consigam com facilidade, encontrar o papelão e montar o fechamento vertical. Ao final, os seguintes princípios de ecodesign foram avaliados no protótipo produzido: (1) facilidade de obtenção dos materiais, (2) utilização de resíduos reaproveitados, (3) baixo custo, (4) solução pensada x problema existente, (5) facilidade de montagem e desmontagem, (6) facilidade de transporte, (7) capacidade de reciclagem ao final da vida útil do sistema e (8) durabilidade. Conclui-se que é possível produzir um fechamento vertical mais sustentável utilizando somente papelão, se todos os princípios de ecodesign apresentados forem pensados ainda na fase de projeto.
\end{abstract}

\section{ABSTRACT}

This research aimed to present and evaluate, according to ecodesign principles, a prototype of vertical partition, using corrugated cardboard as raw material. The study was carried by the bibliographic research, photographic and documentary records made in the second semester of 2017 of the chair of Constructive Processes III, in Faculty of Architecture and Urbanism, in Federal University of Rio de Janeiro (FAU/UFRJ).The design and execution of the prototype was carried out by a group of ten students, who chose the cardboard as the only ray material. This choice came out of the design guideline that suggests that the housing habitants themselves get through easily, find the cardboard and assemble the vertical partition. In the end, the following ecodesign principles were evaluated in the prototype: (1) ease of obtaining the materials, (2) use of recycled and reused waste, (3) low cost, (4) solution x problem (6) ease of transportation, (7) recycling capacity in the end-of-life of the system, and (8) durability. We conclude that it is possible to produce a more sustainable vertical partition using only cardboard if all the principles of ecodesign presented are still thought in the design stage. 


\section{INTRODUÇÃO}

A busca pela sustentabilidade em todos seus aspectos, ambiental, social e econômico, tem sido pauta frequente nas discussões envolvendo o setor da construção civil brasileira (AGOPYAN, JONH, 2011).

O emprego de materiais reaproveitados e reciclados no design e arquitetura tem se verificado como uma prática cada vez mais aceita e difundida, tanto no mercado como no ambiente de ensino.

No design, especificamente, observa-se cada vez mais o uso de materiais reaproveitados e reciclados, como por exemplo: paletes de madeira, vergalhões de aço, garrafas PET, tubos de PVC, containers, papelão, entre outros.

No chamado ecodesign, são integrados aspectos ambientais no projeto e desenvolvimento de produtos, com o objetivo de reduzir seus impactos ambientais negativos ao longo do ciclo de vida. Entre os princípios do ecodesign, podem ser citados: utilização de resíduos como materiais, menor consumo de materiais, estratégias de reuso e reciclagem do produto no fim de sua vida útil, projeto que priorize a facilidade de montagem e desmontagem, aumento da durabilidade, diminuição dos custos, entre outros (BRACKE et al., 2017; ISO 14006, 2011).

Como defendem Cerqueira et al. (2016) o ecodesign pode ser considerado a uma ferramenta de gestão aplicada ao design, voltado para um desenvolvimento mais sustentável, que agrega valor competitivo aos produtos ao longo de todo o ciclo de vida.

Dentre os diferentes materiais ou resíduos que tem sido utilizados no design, um que merece atenção é o papelão ondulado. Ele pode ser definido como uma estrutura formada por um ou mais elementos ondulados fixados a um ou mais elementos planos, em que é utilizado um adesivo colante (ABNT, 2008).

Franco et al. (2014) apontam algumas características importantes que fazem o papelão ondulado ser um material utilizado mundialmente como embalagem: facilidade de produção, baixo custo em relação à sua capacidade de contenção, boa resistência mecânica, térmica, capacidade de ser reciclado, entre outras.

Em 2015 a produção total de papéis no Brasil foi de 10,35 milhões de toneladas, sendo que desse total $53 \%$ foram papéis para embalagens corrugadas. Papéis para embalagem em conjunto com os de imprimir e escrever são os produtos mais importantes para a indústria nacional de papel. Os papéis para embalagens corrugadas no Brasil têm tido crescimento constante e ligeiramente superior ao do PIB para o ano de 2015 (SILVA et al., 2017).
Esses números mostram a importância de se pensar em uma destinação ambientalmente mais amigável para dar a essas embalagens quando não tiverem mais utilidade. Neste sentido, o design com papelão ondulado pode ser considerado um tipo de ecodesign, que tem se destacado como uma alternativa interessante para a produção de objetos leves, de baixo custo, com facilidade de montagem e por ser um material com grande disponibilidade.

Projetos que buscam um design/arquitetura efêmeros (ou temporários) e com foco em abrigos e alojamentos, para pessoas que passaram por algum desastre e que perderam suas moradias, parece ser o contexto ideal para o uso do papelão como matéria prima.

Franco et al. (2014) apontam o importante papel do design para o aproveitamento de embalagens de papelão ondulado, tornando o produto com características bastante particulares.

Na literatura científica são escassos os estudos sobre a aplicação de papelão no design e arquitetura, ainda mais pensando em sistemas de fechamento vertical. Alguns com foco em tubos de papelão, como Salado (2006) e outros utilizando papelão ondulado, como Franco et al. (2014). Razera e Jarek (2014) realizaram experimentos com aparas resultantes da fabricação de caixas de papelão para o uso como acessório em embalagens de transporte. Estudos internacionais como Asdrubali et al. (2016) verificaram o uso de papelóes como matéria prima para painel isolante térmico e acústico para uso na construção civil. Sechi et al. (2016) avaliaram o uso de papelão reciclado para a produção de um isolante acústico. Nota-se que internacionalmente, as pesquisas tem tido o foco para o desenvolvimento de produtos a partir de papelão reciclado, principalmente para a produção de materiais isolantes térmicos e acústicos.

Neste contexto, a presente pesquisa explorou com o uso de papelão ondulado no design de um fechamento vertical os seguintes objetivos: (1) avaliação do protótipo produzido em relação a alguns princípios de ecodesign; (2) apresentação das dificuldades encontradas e proposição de melhorias no processo de projeto e execução; e (3) verificação da forma de apresentação do processo e do protótipo produzido.

\section{MÉTODO DA PESQUISA}

Esta pesquisa foi conduzida a partir de registros documentais e fotográficos realizados no segundo semestre de 2017, na disciplina de Processos Construtivos III, da Faculdade de Arquitetura e Urbanismo da Universidade Federal do Rio de Janeiro (FAU/UFRJ). A disciplina em 
questão está inserida no $6^{\circ}$ período da grade curricular do curso, e faz parte do Departamento de Tecnologia da Construção (DTC).

Foi realizada uma pesquisa bibliográfica sobre o uso de papelão no design e arquitetura a fim de saber os potenciais usos desse material.

O projeto e execução do protótipo foram desenvolvidos por um grupo de dez alunos de graduação de Arquitetura e Urbanismo sob orientação do professor da disciplina.

A seguir são apresentados de forma mais detalhada o processo de projeto e execução do protótipo de fechamento vertical, com base no material entregue pelos alunos ao professor da disciplina.

\subsection{Projeto}

O protótipo foi pensado como uma alternativa para solucionar o problema dos alunos que estavam sem privacidade, devido ao incêndio ocorrido no alojamento estudantil da Universidade Federal do Rio de Janeiro (UFRJ), em agosto de 2017. Eles tiveram que ocupar os espaços comuns do edifício (Figura 1). Neste sentido, o objetivo principal do fechamento vertical proposto é dar privacidade aos usuários, sem que eles precisassem utilizar as barracas.

Figura 01 - Local de intervenção escolhido pelos alunos

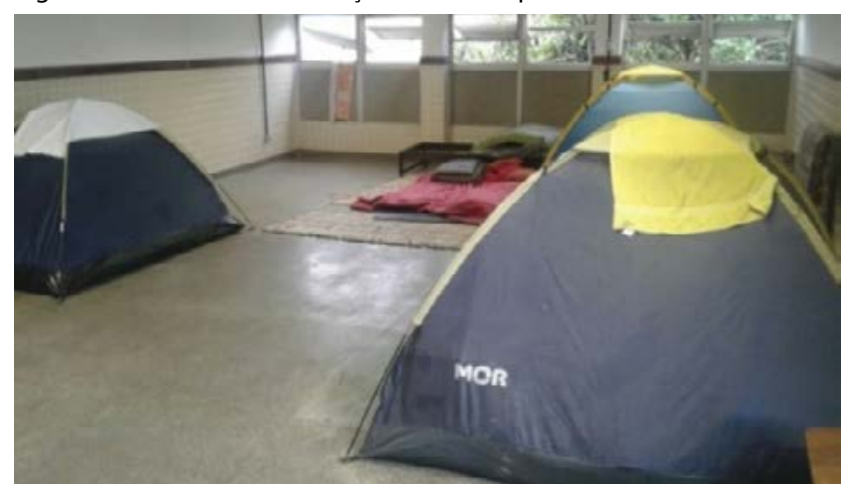

Fonte: Acervo dos alunos - Aline Toledo, Isabella Barbosa, Jones Souza, Karen Fernandes, Kate Valdizan, Letícia Queiroz, Luana Nascimento, Luíza Bovo, Maria Vitória Gomes e Renan Araújo.

O uso do papelão como único material para a confecção do protótipo (Figura 02), surgiu da diretriz de projeto que sugere que os próprios alunos do alojamento consigam com facilidade, encontrar o papelão e montar o fechamento vertical. Foi pensado em um sistema que não precisasse de nenhum procedimento que exija uma técnica mais complexa ou avançada para sua execução (facilidade de montagem), como também sua desmontagem no fim da sua vida útil.
Figura 02 - Módulos de papelão formando o fechamento.

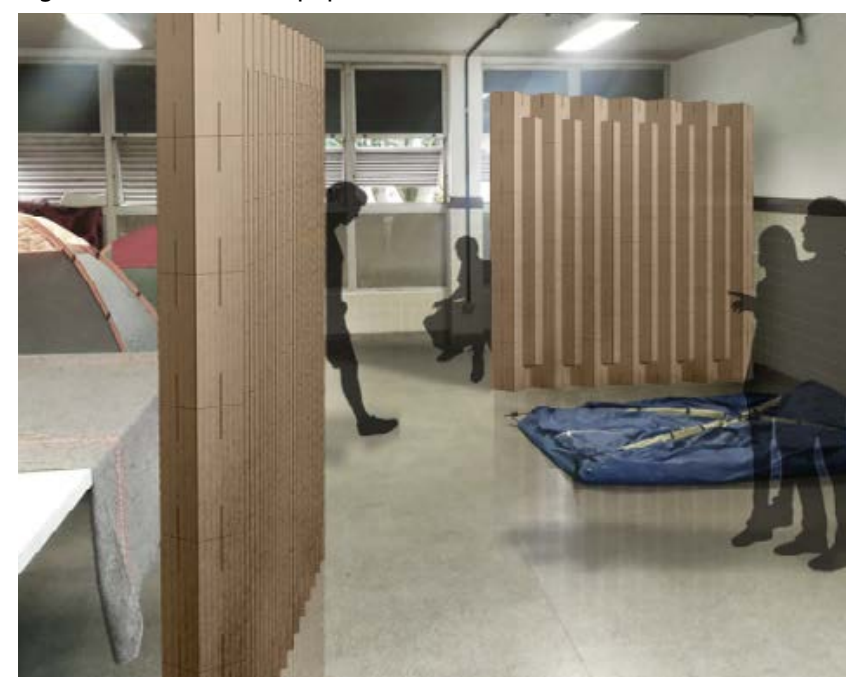

Fonte: Projeto dos alunos - Aline Toledo, Isabella Barbosa, Jones Souza, Karen Fernandes, Kate Valdizan, Letícia Queiroz, Luana Nascimento, Luíza Bovo, Maria Vitória Gomes e Renan Araújo.

A escolha do papelão também teve como justificativas: o fato ser possível realizar o reaproveitamento deste material, que muitas vezes tem seu descarte inadequado e por evitar a extração de recursos naturais; e não possuir nenhum custo de aquisição da matéria prima.

Além de ser facilmente encontrado, o papelão possui a vantagem de ser um material leve, o que permite um fácil transporte e carregamento; ser rígido, característica importante para a estabilidade de um fechamento vertical; e finalmente, pode ser facilmente substituído, quando as peças estiverem no final de sua vida útil.

Uma característica importante que foi pensada para o protótipo foi a capacidade dele ser retrátil e comprimido, facilitando assim seu transporte (Figura 3).

Figura 03 - Representação da capacidade do sistema ser retrátil e comprimido
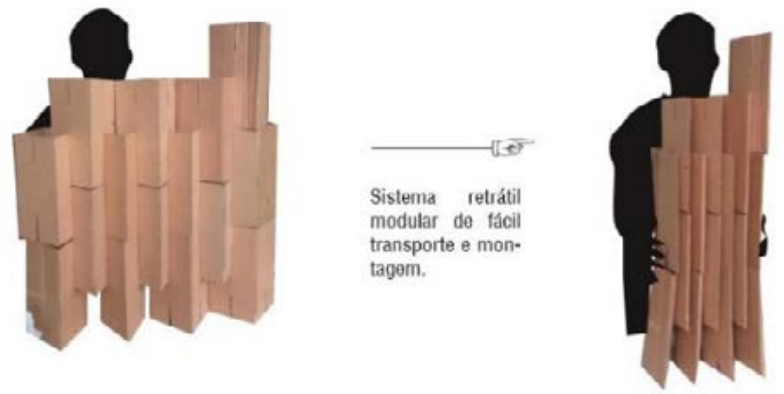

Fonte: Projeto dos alunos - Aline Toledo, Isabella Barbosa, Jones Souza, Karen Fernandes, Kate Valdizan, Letícia Queiroz, Luana Nascimento, Luíza Bovo, Maria Vitória Gomes e Renan Araújo.

Como o uso do protótipo pensado foi uso interno e temporário, não precisou se atentar para algum tipo de tratamento para impermeabilização. 
O elemento do sistema (meio módulo) planificado foi dimensionado em $40 \times 30 \times 22 \mathrm{~cm}$, enquanto o sistema de fechamento vertical ficou com $88 \times 180 \times 22 \mathrm{~cm}$ (Figura 04).

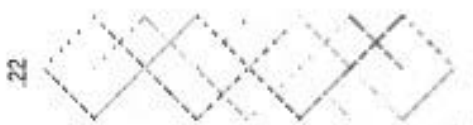

88

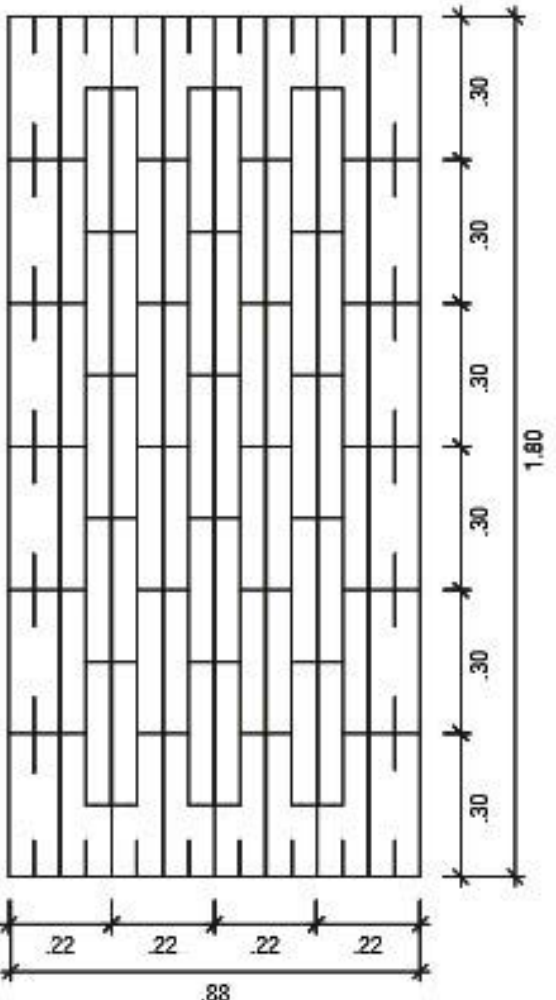

Isabella Barbosa, Jones Souza, Karen Fernandes, Kate Valdizan, Letícia Queiroz, Luana Nascimento, Luíza Bovo, Maria Vitória Gomes e Renan Araújo.

\subsection{Execução}

A execução do protótipo foi realizada no Canteiro Experimental da FAU/UFRJ. O processo de execução foi dividido nas seguintes etapas:

- Coleta do material: os papelões utilizados foram encontrados em lojas ou supermercados, que fariam descarte deste material;

- Separação do material: como os papelões tinham procedência, tamanhos e espessuras diferentes, foi necessário selecionar aqueles que poderiam ser utilizados para a confecção do protótipo;

- Desenho dos módulos: definida a maneira como os módulos seriam montados, foram impressos os moldes para o desenho das peças (Figura 05 e 06);

- Montagem dos módulos: cada duas peças equivalem a um módulo, sendo as duas encaixadas dispensando o uso de qualquer material colante (Figura 07);

- Montagem do sistema de fechamento: encaixa-se todos os módulos. O fechamento pode ser sanfonado e facilmente transportado (Figura 08).

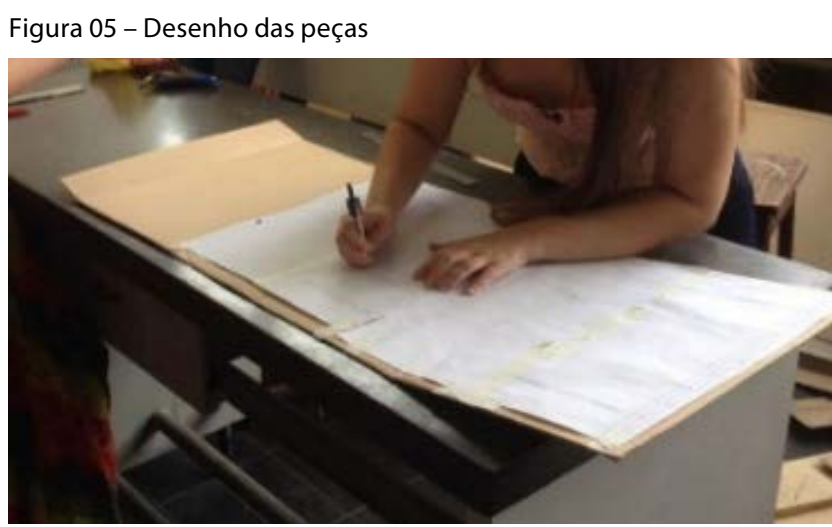

Fonte: Acervo dos alunos - Aline Toledo, Isabella Barbosa, Jones Souza Karen Fernandes, Kate Valdizan, Letícia Queiroz, Luana Nascimento, Luíza Bovo, Maria Vitória Gomes e Renan Araújo.

Figura 06 - Elemento do sistema executado

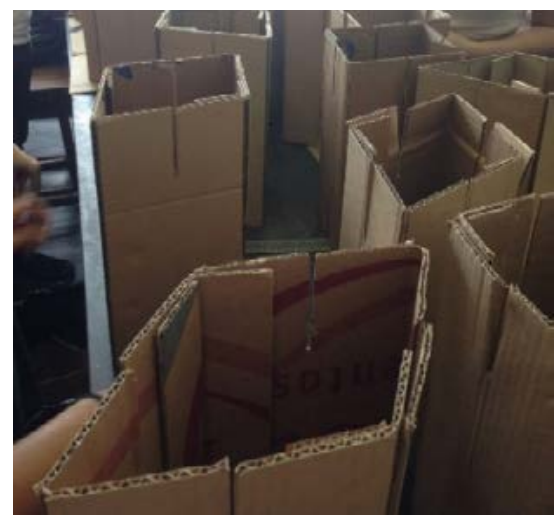

Fonte: Acervo dos alunos - Aline Toledo, Isabella Barbosa, Jones Souza, Karen Fernandes, Kate Valdizan, Letícia Queiroz, Luana Nascimento, Luíza Bovo, Maria Vitória Gomes e Renan Araújo.

Figura 07 - Módulo montado

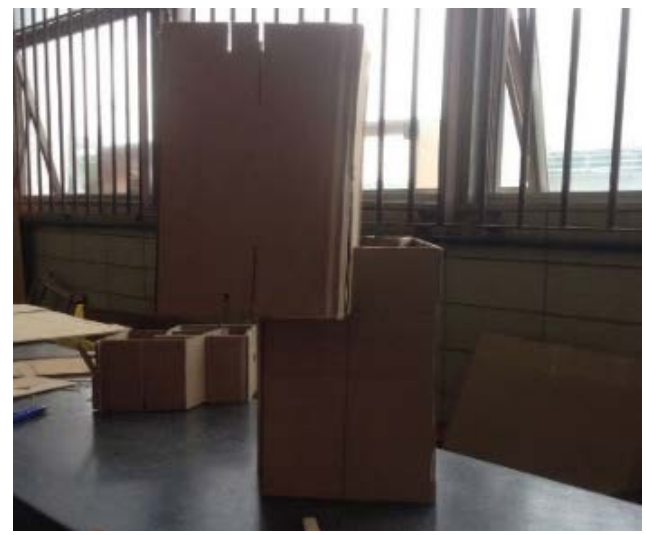

Fonte: Acervo dos alunos - Aline Toledo, Isabella Barbosa, Jones Souza, Karen Fernandes, Kate Valdizan, Letícia Queiroz, Luana Nascimento, Luíza Bovo, Maria Vitória Gomes e Renan Araújo. 
Figura 08 - Fechamento vertical montado

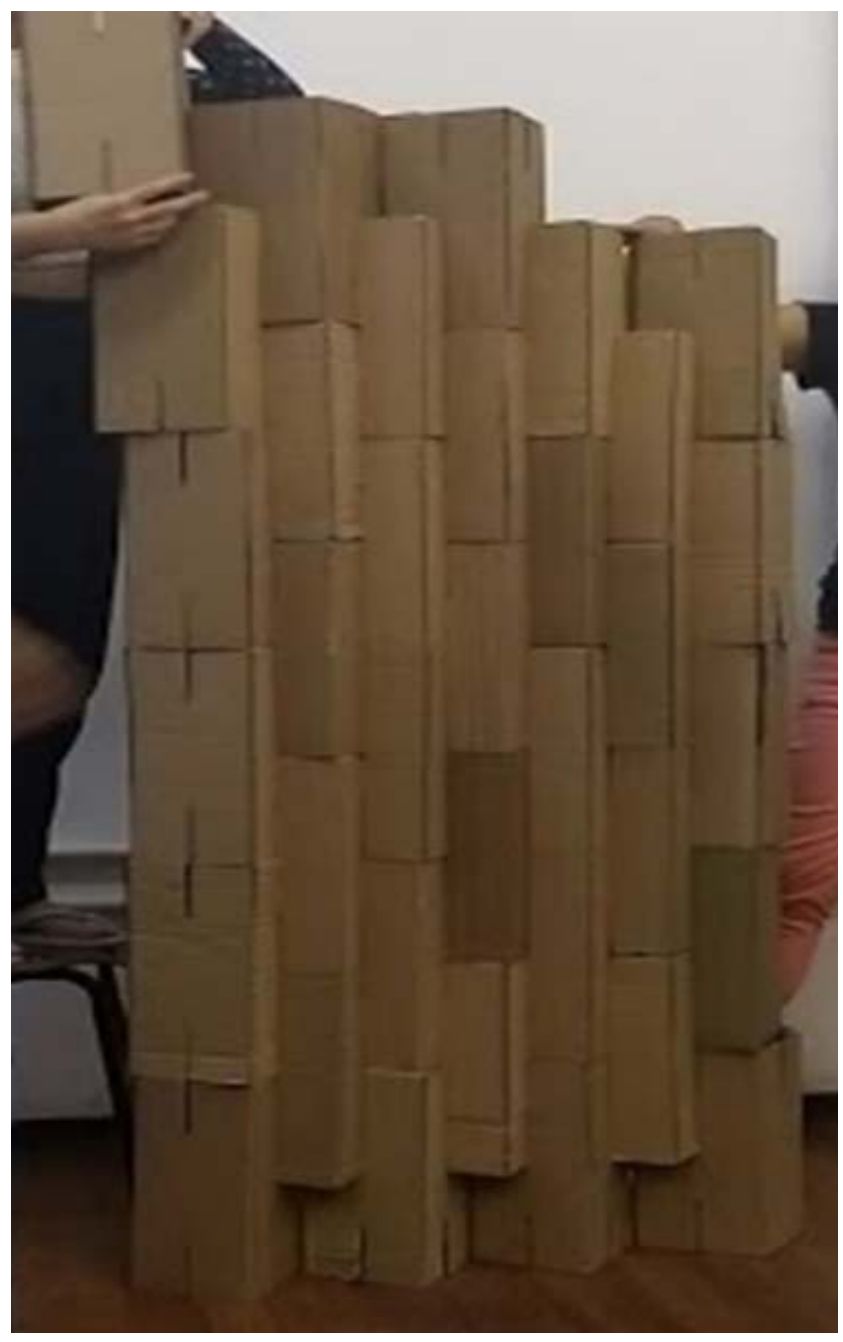

Fonte: Acervo dos alunos - Aline Toledo, Isabella Barbosa, Jones Souza, Karen Fernandes, Kate Valdizan, Letícia Queiroz, Luana Nascimento, Luíza Bovo, Maria Vitória Gomes e Renan Araújo.

Com os módulos já confeccionados, a montagem do sistema pode ser realizada em 10 minutos, sendo necessário duas pessoas.

\subsection{Relação do projeto com princípios do ecodesign}

A partir da revisão bibliográfica, com base nos estudos de Bracke et al. (2017) Ceschin e Gaziulusoy (2016), Dekoninck et al. (2017), e da norma ISO 14006 (2011), o sistema de fechamento vertical produzido foi avaliado conforme os seguintes princípios de ecodesign:

- Facilidade de obtenção dos materiais;

- Utilização de resíduos reaproveitados ou reciclados;

- Baixo custo;

- Solução pensada x problema existente;

- Facilidade de montagem e desmontagem;

- Facilidade de transporte;
- Capacidade de reciclagem ao final da vida útil do sistema;

- Durabilidade.

\section{RESULTADOS E DISCUSSÃO}

3.1 Avaliação do protótipo produzido em relação a alguns princípios ecodesign

Os itens mais importantes que merecem destaque no protótipo desenvolvido, em relação ao ecodesign são:

- Facilidade de obtenção dos materiais: o fato de ser produzido somente com um tipo de material e a grande disponibilidade de papelão em diferentes lugares.

- Utilização de resíduos reaproveitados: os papelões, primeiramente utilizados como embalagens, se tornam resíduos. Uma característica importante é que eles foram reaproveitados do jeito que foram encontrados, sem a necessidade de nenhum tratamento adicional, o que deixa o processo ainda mais simplificado.

- Baixo custo: um dos pilares da sustentabilidade é o aspecto econômico. Neste sentido, esse protótipo consegue satisfazer muito bem esse requisito, pois não teve nenhum custo.

- Solução pensada x problema existente: Como o problema pensado é de caráter temporário, não houve a necessidade de se pensar em um sistema de elevada durabilidade. O fato do sistema ser facilmente produzido e montado também ajuda a solucionar essa fraqueza de baixa durabilidade do sistema. Os módulos (ou o sistema como um todo) podem ser facilmente substituídos. É importante que o aluno saia da disciplina com esse pensamento, sabendo primeiro qual o problema a ser solucionado para depois pensar em um projeto que o atenda bem, pensando na materialidade mais adequada. Do ponto de vista da sustentabilidade é interessante que seja pensado em uma solução otimizada, com a maior economia de recursos e que ao mesmo tempo consiga atender o problema a ser solucionado.

- Facilidade de montagem e desmontagem: A facilidade de montagem e desmontagem foram itens fundamentais neste projeto, que só conseguiram ser realizadas com um tempo dispendioso para o projeto do elemento básico do sistema, pensando em quais dimensões seriam as melhores, que conseguissem proporcionar uma estabilidade adequada e que fosse possível de ser executada. O fato de não precisar de nenhum outro material além do papelão para a montagem ou desmontagem é um item importante do projeto. 
- Facilidade de transporte: A capacidade do sistema ser sanfonado e comprimido facilita o transporte do sistema. Esse item trouxe um desafio durante a etapa de projeto, em que se precisou pensar em qual dimensões mais adequadas para que o processo de sanfonamento fosse possível depois que o fechamento já estivesse pronto.

- Capacidade de reciclagem ao final da vida útil do sistema: quando ele for desmontado, não há a necessidade de separar os materiais, o papelão como resíduo pode ser reciclado e enviado para um único lugar, portanto, torna o gerenciamento de resíduos muito mais simplificado. O papelão pode ser classificado como resíduo classe $B$ (conforme a resolução CONAMA 307 (BRASIL, 2002)).

- Durabilidade: Este é o item de pior desempenho do sistema, tendo em vista que ele é de papelão e sem nenhum tratamento. Um tratamento com verniz poderia até melhorar a durabilidade do fechamento, no entanto, elevaria consideravelmente os custos e tempo de execução. Como o sistema tem a intenção de ser temporário, o uso de algum tratamento iria contra a principal diretriz do projeto. Por fim, um tratamento de verniz, pode impossibilitar a reciclagem do material no final da sua vida útil, além de tornar um resíduo considerado Classe B para Classe D - resíduo perigoso, que possui uma destinação final mais difícil e onerosa. A partir dessa avaliação verifica-se que o protótipo desenvolvido pelos alunos consegue atender bem quase todos os princípios de ecodesign destacados, além de ser uma solução interessante e eficiente para o local de intervenção selecionado pelos alunos.

É importante ressaltar que todos esses princípios foram pensados ainda na fase de concepção do projeto e por isto o projeto teve sucesso.

\subsection{Dificuldades encontradas e proposição de} melhorias no processo de projeto e execução

Dentre as dificuldades encontradas, a coleta de papelão em boas condições foi uma das mais críticas. Em muitos casos foram encontrados papelões amassados, sujos, rasgados e sem dimensões padronizadas (forma, tamanho e espessura).

Com o papelão encontrado, o módulo pensado inicialmente, teve que ser reduzido, já que quanto maior a peça, menos estável ficava o fechamento. Entretanto, também foi observado que se o módulo ficasse muito pequeno, o mesmo teria dificuldades para sanfonar, perdendo uma das caraterísticas originais do projeto. A solução foi chegar a um meio termo, que atendesse o tamanho médio das caixas disponíveis.

A parte da estruturação também teve que ser repensada, de maneira que cada módulo possuísse duas peças, o que inclusive, possibilitou o aproveitamento de mais caixas de papelão, e que em seu interior, o encaixe se fizesse em forma de cruz, dando maior rigidez ao sistema.

Como sugestão de melhoria, pode ser pensado em uma forma de diminuir o tempo despendido no processo de montagem do sistema, e ter menos módulos. Neste aspecto, seria interessante que as caixas de papelão utilizadas, tivessem maior altura, de maneira que precisasse de menos módulos para atingir a altura desejada.

\subsection{Forma de apresentação do processo e do protótipo produzido}

Como apresentação do protótipo foi produzido um Manual de Uso e Operação para a facilitação da montagem do fechamento pelos estudantes do alojamento (Figura 09).

Figura 09 - Manual de Uso e Operação: etapas do processo de execução

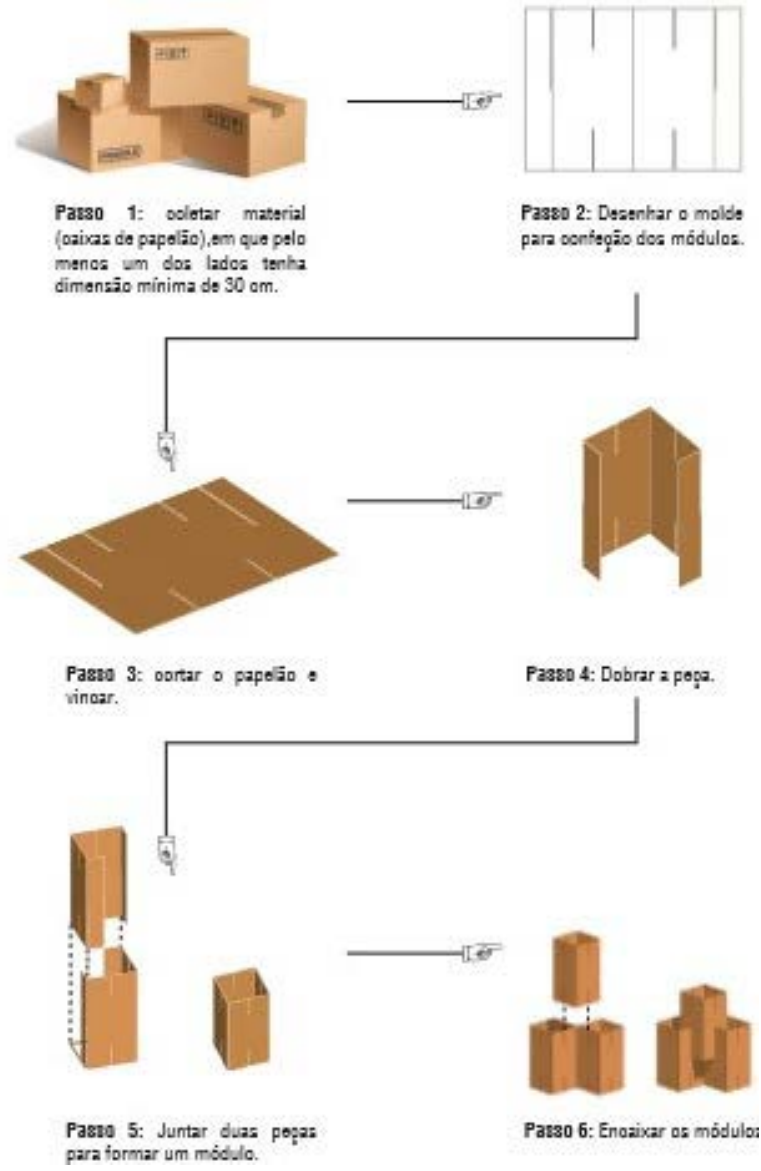

Fonte: Projeto dos alunos - Aline Toledo, Isabella Barbosa, Jones Souza, Karen Fernandes, Kate Valdizan, Letícia Queiroz, Luana Nascimento, Luíza Bovo, Maria Vitória Gomes e Renan Araújo. 
Para a apresentação aos alunos da classe e professor, ao final da disciplina, foi produzido um vídeo de três minutos que mostra desde a escolha do local de intervenção, projeto e execução do protótipo.

A utilização de vídeo como recurso de apresentação foi bastante interessante pois é uma forma menos monótona que slides e posteriormente pode ser facilmente compartilhado nas redes sociais, sendo portanto, uma forma mais eficaz de divulgar o que foi produzido na disciplina e uma maneira de disseminar os conceitos de ecodesign discutidos.

\section{CONCLUSÕES}

Na disciplina de Processos Construtivos III do curso de Arquitetura e Urbanismo da Universidade Federal do Rio de Janeiro (FAU/UFRJ) um grupo de alunos projetou e executou um protótipo de fechamento vertical utilizando somente papelão ondulado reaproveitado como matéria prima, sob orientação do professor.

A partir da revisão bibliográfica foi avaliado o fechamento vertical em relação a alguns princípios importantes de ecodesign, entre eles: utilização de resíduos, facilidade de montagem e desmontagem, facilidade de transporte, entre outros. Observou-se que o protótipo produzido atendeu satisfatoriamente a maioria dos princípios avaliados e se mostrou como uma solução interessante e eficiente para o local de intervenção escolhido pelos alunos, nesse caso, um alojamento estudantil.

Dentre as dificuldades encontradas ao longo do processo, a seleção de papelões com qualidade desejada se mostrou uma das etapas mais críticas.

Como forma de apresentação do protótipo foi produzido um Manual de Uso e Operação para os alunos do alojamento e produção de um vídeo para apresentação ao final da disciplina, que pode posteriormente ser divulgado em redes sociais.

Ressalta-se a importância de se pensar nos princípios de ecodesign avaliados ainda na fase de concepção do produto.

Por fim, esta pesquisa traz uma contribuição importante no contexto do ecodesign, mostrando que é possível produzir um fechamento vertical mais sustentável e mostrando a importância de discutir essa temática durante um curso de graduação.

\section{AGRADECIMENTOS}

O autor gostaria de agradecer à Faculdade de Arquitetura e Urbanismo da Universidade Federal do Rio de Janeiro (FAU/UFRJ), em especial o Departamento de
Tecnologia da Construção (DTC), por possibilitar a discussão da temática sobre sustentabilidade e ecodesign em uma de suas disciplinas de graduação e o desenvolvimento de protótipos utilizando materiais alternativos no Canteiro Experimental da faculdade.

O autor (professor da disciplina) também gostaria de parabenizar os alunos: Aline Toledo, Isabella Barbosa, Jones Souza, Karen Fernandes, Kate Valdizan, Letícia Queiroz, Luana Nascimento, Luíza Bovo, Maria Vitória Gomes e Renan Araújo pelo esforço e dedicação durante o exercício proposto na disciplina.

\section{REFERÊNCIAS}

AGOPYAN,V.jJONH,V.M.ODesafiodaSustentabilidade na Construção Civil. Série Sustentabilidade, v. 5. 1. ed. São Paulo: Editora Blucher, 2011.

ASDRUBALI, F.; PISELLO, A. L ALESSANDRO, F. D.; BIANCHI, F.; FABIANI, C.; CORNICCHIA, M.; ROTILI. A. Experimental and numerical characterization of innovative cardboard based panels: Thermal and acoustic performance analysis and life cycle assessment. Building and Environment, v. 95, p. 145-159. 2016.

ASSOCIAÇÃO BRASILEIRA DE NORMAS TÉCNICAS (ABNT). NBR 5985. Embalagem de papelão ondulado Terminologia. Rio de Janeiro, 2008.

BRACKE, S.; YAMADA, S.; KINOSHIT, Y; INOUE, M.; YAMADA, T. Decision making within the conceptual design phase of eco-friendly products. Procedia Manufacturing, v. 8, p. 463-470. 2017.

BRASIL. 2002. Resolução $\mathbf{n}^{\circ}$ 307, de 5 de Julho de 2002. Disponível: <http://www.mma.gov.br/port/conama/legiabre.cfm?codlegi=307>. Acesso em 14 out.2017.

CERQUEIRA, V.; RODRIGUEZ, L.; LAUREANO, J. V.; VILLAPOUCA, L. Desenvolvimento De produtos sustentáveis, a partir Das relações entre Design universal e ecodesign. Mix Sustentável, v. 3, p. 121. 131.

CESCHIN, F.; GAZIULUSOY, I. Evolution of design for sustainability: From product design to design for system innovations and transitions. Design Studies, v. 47, p. 118-163. 2016.

DEKONINCK, E. A. et al. Defining the challenges for ecodesign implementation in companies: 
Development and consolidation of a framework. Journal of Cleaner Production, v. 135, n.1, p. 410-425. 2016.

FRANCO, A.; SALES, R. B. C.; MOHALLEM, N. D. S. Design para mobiliario ecoeficiente utilizando papelão ondulado. Anais...11 P\&D Design, Gramado, RS, Outubro, 2014.

ISO. ISO 14006: Environmental Management Systems e Guidelines for Incorporating Ecodesign. 2011.

LAMÉ, G.; LEROY, Y.; YANNOU, B. Ecodesign tools in the construction sector: Analyzing usage inadequacies with designers' needs. Journal of Cleaner Production, v. 148, n.1, p. 60-72. 2017.

RAZERA, D. L.; JAREK, J. M. Design e inovação no aproveitamento sustentável de resíduos em empresa de papelão: reaproveitamento de aparas com meIhor valor agregado. Anais...11\% P\&D Design, Gramado, RS, Outubro, 2014.

SALADO, G. C. Construindo com tubos de papelão: Um estudo da tecnologia desenvolvida por Shigeru Ban. Dissertação (Mestrado). São Carlos: Escola de Engenharia de São Carlos - Universidade de São Paulo, 2006. 186p.

SECCHI, S.; ASDRUBALI, F.; CELLAI, G.; NANNIPIERI, E.; ROTILI, A.; VANNUCCHI, I. Experimental and environmental analysis of new sound-absorbing and insulating elements in recycled cardboard. Journal of Building Engineering, v. 5, p. 1-12. 2016.

SILVA, C. A. F.; BUENO, J. M.; NEVES, M. R. A indústria de celulose e papel no Brasil. Guia ABTCP Fornecedores e Fabricantes. 2017. 